\title{
Tras la huella católica en los sindicatos. Una aproximación comparativa a los casos de Mendoza y Córdoba (1943-1945)
}

\author{
Jessica Blanco
}

CIFFyH - Conicet/UNC

jessieblanco@yahoo.com.ar

Title: Following the Catholic footsteps in the trade unions. A comparative approach to the cases of Mendoza and Córdoba (1943-1945)

Resumen: El artículo analiza la gravitación de la Iglesia en la historia del sindicalismo, atendiendo a los casos de la Federación de Sindicatos Católicos Obreros de Mendoza, y al proyecto sindical del Círculo Católico de Obreros de Córdoba, entre 1943 y 1945 . Cabe entender dichas propuestas en un contexto político represivo de las tendencias sindicales izquierdistas, y en un marco religioso de madurez laical de índole social. Empero, los contextos politico-ideológicos y las trayectorias e influencias en el entramado sindical y politico de la época invitan a un estudio comparativo entre ambas situaciones.

Palabras clave: asociaciones laicales - sindicatos - Mendoza - Córdoba

\begin{abstract}
The article analyzes the gravitation of the Church by attending to cases of the Federation of Catholic Workers' Unions of Mendoza and the trade union project carried out by the Catholic Circle of Workers of Cordoba between 1943 and 1945. These proposals should be understood in a political context of repression of leftist trade union tendencies, and in a religious framework of maturity of lay initiatives of a social nature. However, the political and ideological contexts and the trajectories and influences on the trade union and political fabric of the time, invite a comparative study of both situations.
\end{abstract}

Keywords: lay associations - trade unions - Mendoza - Córdoba

Recepción: 30 de mayo de 2018. Aprobación: 15 de julio de 2018 .

(Archivos, año VII, $\mathrm{n}^{\circ} 13$, septiembre de 2018, pp. 75-95) 


\section{Introducción}

En la década de 1940, la acción sindical confesional de asociaciones laicales como los Círculos Católicos de Obreros (CCO) o la Acción Católica Argentina (ACA) formó parte de la agenda de preocupaciones de ambas agrupaciones a nivel nacional, expresada en congresos y asambleas. Así, la organización católica sindical constituyó uno de los asuntos centrales del IX Congreso de los CCO celebrado en 1942, materializada a los pocos meses en la Confederación Católica de Trabajadores Agremiados, que se vio reforzada a partir del golpe de Estado de 1943 por la constitución de varios sindicatos más. ${ }^{1}$ Respecto de la ACA, uno de los temas de las reuniones especializadas del Secretariado Económico Social en su Segunda Asamblea Nacional celebrada entre abril y mayo de 1943 se centró en la promoción de la sindicalización cristiana. De todas maneras, este asunto no aparecía en el plan económico-social de $1944 .^{2}$

En algunas provincias, este anhelo logró concretarse a través de sindicatos promovidos por los asesores eclesiásticos de los Círculos, como en Córdoba y Santa Fe. Por su parte, la ACA fue fundamental en la promoción de centrales sindicales católicas de dispar éxito, como la Federación de Asociaciones Gremiales Cristianas, fundada a fines de 1942 en Tucumán y compuesta exclusivamente por mujeres; y la Federación de Sindicatos Católicos Obreros, creada en 1944 en Mendoza.

Al respecto, este artículo se propone analizar la intervención de agentes eclesiásticos y laicos y la gravitación de la doctrina social de la Iglesia en la historia del sindicalismo durante el gobierno militar de 1943-1946, atendiendo a los casos de la Federación de Sindicatos Católicos Obreros (FSCO) de Mendoza, y al proyecto sindical llevado a cabo por el Círculo Católico de Obreros de Córdoba (CCOC). Cabe entender a dichas propuestas en un contexto político de represión a las tendencias sindicales izquierdistas y en el marco religioso de promoción gremial confesional de la ACA y de una probable emulación de la Confederación Católica de Trabajadores Agremiados.

El presente trabajo pretende constituir un aporte a la imbricación mutua entre sindicalismo y catolicismo en clave comparada. En efecto, las diferencias de los contextos gremiales de surgimiento de ambas y de las trayectorias y las influencias en el entramado sindical y politico

1. Testimonio del padre Emilio Ballardini (asesor de secretaria de las Vanguardias Obreras Católicas de los CCO) en Orden Cristiano, $\mathrm{n}^{\circ}$ 137, 25 de julio de 1947, citado en Bauer (1999: 142); Actas de sesiones de la Junta de Gobierno de la Federación de los Círculos Católicos de Obreros, acta 1885, 23 de enero de 1945, p. 80.

2. Boletin Oficial de la Acción Católica Argentina, abril de 1943, p. 184; junio de 1943, pp. 367-368; marzo de 1944, p. 135. 
de la época invitan a un estudio comparativo entre ambas situaciones, considerando como variables de análisis la inserción de estas iniciativas gremiales confesionales en el mapa sindical vernáculo, las configuraciones de poder en el interior de la Iglesia y la relación entre ésta y el gobierno militar. Aquí es cuando la tensión entre historia regional e historia comparada resulta enriquecedora, puesto que la perspectiva comparada posibilita visualizar, como en un juego de luces y sombras, las especificidades y semejanzas entre historias locales que encuentran significación con el todo.

\section{3-1945, auge y ocaso de la acción sindicalizadora del Círculo Católico de Obreros de Córdoba}

\section{Contexto económico y sindical en Córdoba}

Acorde con una economía predominantemente rural y una estructura industrial desarrollada sobre la base de la industria liviana, en la Córdoba de entreguerras el mayor número de gremios se correspondió con estos sectores, donde eran poderosos los comunistas. Durante los gobiernos radicales (1936-1943), los socialistas predominaron en los gremios del sector terciario y de servicios (empleados de comercio, ferroviarios, tranviarios), mientras la prédica comunista fue preponderante entre los obreros gráficos, rurales (oficios varios, estibadores y conductores de carros y camiones) y de la producción (construcción, metalurgia y alimentación), que cubrian el mayor porcentaje de la actividad industrial. La presencia anarquista se encontraba en los sindicatos de cocineros y pasteleros, panaderos y oficios varios. ${ }^{3}$

En 1936, el cambio de la estrategia comunista a favor de la formación de los frentes populares permitió el acercamiento entre los sindicatos comunistas y socialistas, que en 1938 fundaron la Federación Obrera Provincial. La comisión directiva de ese año reflejó el equilibrio de fuerzas entre ambas tendencias, con una importante presencia de dirigentes del gremio de la construcción. Esta unidad entre socialistas y comunistas se mantuvo hasta fines de 1940, en que los últimos pretendieron alinear a la central a la política soviética de neutralidad. ${ }^{4}$ La posibilidad de acercamiento se produjo recién un año después, cuando el ataque de Alemania a la Unión Soviética en junio de 1941 condujo nuevamente a los comunistas a sumarse al frente antifascista. Sin embargo, el golpe de

3. La Voz del Interior, 25 de agosto de 1940, p. 12, y 4 de mayo de 1941, p. 22; Ferrero (2009: 92-93 y 97).

4. La Voz del Interior, 9 y 20 de noviembre de 1940, p. 11; El País, 9 de noviembre de 1940, p. 10; Ferrero (2009: 101). 
junio de 1943 encontrará a los socialistas en la Comisión Cooperadora de la CGT, liderada por el ferroviario Bruno Herrera, y a los comunistas en la por ese entonces Unión Obrera Provincial (Ferrero, 2009: 103). En sintesis, en Córdoba la influencia de comunistas y socialistas en los distintos sectores productivos y de servicios replicaba a grandes rasgos la representación a nivel nacional.

De manera paralela, en la década de 1930 la acción de la Iglesia para contrarrestar la obra de estas tendencias se expresó en una labor de formación social y de preparación sindical cristiana, promoviendo organizaciones gremiales como el sindicato de costureras, el centro de empleadas católicas y la Asociación Católica de Enfermeras propiciados por la AC de Córdoba (ACC) (Blanco, 2008). En 1938 existió un intento de fundación de un gremio de la construcción en la localidad de Hernando por gestiones del presidente del CCOC, para oponerse a otro de orientación "político-comunista", ${ }^{5}$ que formó parte de un proyecto de sindicalización promovido unos años atrás por la Junta de Gobierno de la Federación de los CCO.

Mutualismo, protección y asesoramiento gremial, bases de la acción sindicalizadora del Círculo Católico de Obreros de Córdoba

La actividad gremial en el país se vio seriamente afectada a partir del golpe de Estado de 1943. En correspondencia con lo que sucedia en todo el país, esta fue restringida a través de la intervención de la CGT local, la clausura de todas las entidades gremiales y -por disposición del gobierno nacional- la suspensión de asambleas, reuniones públicas y comisiones directivas gremiales. La reacción de los sindicatos -principales blancos de estas medidas por considerarlos subversivos- fue la cautela, evitando cualquier proclama o pronunciamiento sobre el nuevo gobierno militar, a diferencia de lo enunciado por las centrales gremiales nacionales que expresaron su aval a las medidas del gobierno.

Es en este contexto donde la agremiación del CCOC cobró vigor, a partir de dos hechos destacados que actuaron como condiciones de posibilidad: uno, de carácter interno, fue el nombramiento en mayo de 1943 del viceasesor de la entidad Rafael Moreno, que vino a renovar

5. Actas de sesiones de la Comisión Directiva del Círculo Católico de Obreros de Córdoba, 1 de agosto de 1942; Círculo Católico de Obreros, Cincuentenario de los Círculos Católicos de Obreros de la República Argentina. 1892-1942, Buenos Aires, 1943, p. 188; Correspondencia entre la Junta y el Círculo de Obreros de Córdoba, 4, 14, 21 y 27 de febrero y 18 de mayo de 1938. Recordemos que los comunistas tenían una presencia muy importante en los gremios de la construcción. 
una alicaída asociación. ${ }^{6} \mathrm{E} 1$ segundo, de índole externa, lo constituyó el decreto nacional 2.669 de asociaciones profesionales de julio de 1943, que completaba el cuadro represivo hacia las dirigencias sindicales que actuaban politicamente: reglamentaba la organización y el funcionamiento de las asociaciones patronales y obreras, condicionando su accionar al reconocimiento por parte del gobierno de su personeria jurídica. ${ }^{7}$ Así, el proyecto de sindicalización tímidamente bosquejado años atrás por el CCOC se activó en una coyuntura de espacios gremiales en disponibilidad: la represión del gobierno militar a las tendencias de izquierda durante los primeros meses de gestión y la legislación que condicionaba el accionar sindical. Como afirma Achával Becú (2010: 215-216) otro factor que seguramente favoreció el accionar del CCOC fue la representación del nacionalismo católico en la política laboral de la provincia vía Narciso Rey Nores -desde agosto de 1943 a cargo del Departamento Provincial del Trabajo (DPT)-, un dirigente de la ACC que como abogado especializado en derecho laboral habia sido asesor de sindicatos católicos.

El plan bosquejado y llevado a la práctica por el CCOC utilizaba estrategias y actividades ya probadas con éxito. El punto de partida para atraer a nuevos trabajadores sería el mutualismo -mediante la creación de la categoría de socio mutualista-, y la "conversión" se realizaría a través de conferencias y el contacto personal ejercido por la militancia. Otro medio de persuasión, para nada desdeñable en una época en la que pocos gremios contaban con un espacio propio de reunión, era el préstamo del local a los sindicatos para celebrar sus encuentros. El objetivo principal era conquistar las bases sindicales cuyas dirigencias habian sido decapitadas:

La disposición del Superior Gobierno de la Nación disolviendo a todos los gremios obreros hasta tanto no se dicten los nuevos reglamentos a los cuales tendrán que ajustarse para ser tales, ha impulsado al Círculo a iniciar una acción de captación de estos gremios dispersos a fin de ganarse para la causa que defiende. ${ }^{8}$

6. A principios de la década de 1940, el Círculo estaba transitando una crisis importante por merma de miembros y falta de renovación dirigencial (incluso no se deja renunciar a algunos dirigentes y al asesor espiritual). Actas de sesiones de la Comisión Directiva del Círculo Católico de Obreros de Córdoba, 8 de abril de 1943, pp. 311-314; 11 de septiembre de 1941, p. 176; 19 de agosto de 1943, p. 350.

7. La Voz del Interior, 21 de julio de 1943, p. 5.

8. Nota del 4 de noviembre de 1943 del CCOC a la Junta de Gobierno de los Círculos. 
La categoría de socio mutualista se creó como respuesta al pedido de algunos dirigentes sindicales de que los afiliados a sus sindicatos pudieran asociarse solamente a la mutualidad del Círculo para contar con esos beneficios. Esto no significaba convertirse en socio de la institución, pero el CCOC no desaprovechó este vínculo. Si bien se reconocía que muchos de estos trabajadores no cumplian con los "requisitos morales" para integrarse a la asociación, se confiaba en su posterior formación vía conferencias. ${ }^{9}$ Cabe aclarar que el socio mutualista no pagaba una cuota mensual a título personal, puesto que el nexo entre el trabajador y la asociación católica era a través del sindicato, encargado de la erogación ante el Círculo para que sus afiliados tuvieran cobertura mutual.

Así, los sindicatos no aparecen como pasivos receptores en esa propuesta; se trataba más bien de una negociación en la cual los trabajadores -o por lo menos las dirigencias sindicales- valoraban al CCOC por su capacidad de proporcionar cobertura mutual minima, local de reuniones y -en ese contexto de proscripción de actividades gremiales y políticas- la protección de una asociación que comulgaba con los mismos preceptos nacionalistas católicos que el gobierno militar. Asimismo, en el acercamiento de algunos grupos de noveles sindicalistas que reconocían "un absoluto desconocimiento de lo gremial"10 influyó el asesoramiento en esta área impartido por Moreno:

Nos enteramos de que el cura Moreno había ayudado a los cerveceros, a los tranviarios y a otros gremios y entonces fuimos a hablarle. El cura contestó que con mucho gusto nos explicaría cómo hacerlo. Nos daba conferencias y era muy vivo: en sus primeras charlas no resaltaba a la Iglesia... ${ }^{11}$

La injerencia formativa del CCOC iba más allá de la creación de sindicatos y la "organización mutual de los diferentes gremios": ${ }^{12}$ la asociación también se encargó de redactar nuevos estatutos para el

9. Actas de sesiones de la Comisión Directiva del Círculo Católico de Obreros de Córdoba, 30 de marzo de 1944, p. 391; Nota del 4 de noviembre de 1943 del CCOC a la Junta de Gobierno de los Círculos.

10. Testimonios de Vicente Moyano y Julio Murúa, fundadores del sindicato USEOCPE (desde 1946 Luz y Fuerza), reproducido en Roldán (1978: 103).

11. Testimonio de Julio Murúa reproducido en Roldán (1978: 103). Según Horacio Carignano, trabajador en la empresa desde 1943 y uno de los miembros de la comisión provisoria, fue el cura quien los invitó: Electrum $50^{\circ}$ aniversario, Sindicato de Luz y Fuerza de Córdoba, Córdoba, junio de 1994, p. 11.

12.Actas de sesiones de la Comisión Directiva del Círculo Católico de Obreros de Córdoba, 10 de febrero de 1944 , p. 382. 
sindicato del transporte FOTAI y para otros sindicatos; ${ }^{13}$ Moreno tenía reuniones mensuales con las comisiones directivas de los gremios y encabezaba delegaciones de trabajadores (metalúrgicos, tranviarios, de ómnibus) que se entrevistaban con los interventores federales y presentaban memoriales y petitorios con claras influencias de la doctrina social católica. Otros servicios brindados por el CCOC que permitian influir en la vida interna de los sindicatos eran el asesoramiento para la elaboración y discusión de pliegos de condiciones y contratos colectivos y la asistencia profesional en causas civiles y criminales derivadas del trabajo, ${ }^{14}$ aportes nada despreciables sobre todo para dirigentes con escasa o nula experiencia sindical.

La activa tarea de promoción de sindicatos católicos por parte de Moreno involucraba según fuentes del CCOC a más de 4.000 trabajadores y se refería a la "reestructuración" de gremios ya existentes (los tres del transporte de pasajeros: FOTAI, AOITA y SOTA), y la creación de otros, como la Unión Obreros Tranviarios de Córdoba, la Unión Sindical de Empleados y Obreros de las Compañias Productoras de Electricidad (USEOCPE, luego Luz y Fuerza), el Centro de Obreros de Estaciones de Servicios, Mecánicos y Anexos, el Sindicato Obreros Unidos de la Industria Vitivinícola, la Unión Obrera de la Industria Cerámica de Córdoba, el Sindicato Católico de la Industria Cervecera, la Unión de Empleados de Teatros y Cines, el Sindicato de Obreros del Jockey Club, la Asociación de Inspectores del Transporte Automotor y el Sindicato de Obreros del Portland. Asimismo se estaban organizando los gremios de mudanzas, electricistas, biseladores, confiteros y sastres, entre otros. ${ }^{15}$

13. Actas de sesiones de la Comisión Directiva del Círculo Católico de Obreros de Córdoba, 16 de diciembre de 1943, p. 377; Memoria, 30 de junio de 1943 al 30 de junio 1944 del CCOC enviada el 22 de agosto de 1944 a la Junta de Gobierno de los Círculos, p. 3. El estatuto de los obreros y empleados de las Compañías de Electricidad fue elaborado conforme a las directivas de la Iglesia y contemplaba hasta un asesor eclesiástico. Libro de Actas, p. 1; Estatuto primitivo transcripto en Actas en Roldán, 1978: 148. El memorial entregado al interventor federal León Scasso en enero de 1944 por el gremio de los metalúrgicos, creado también con apoyo de Moreno, dejaba expuestas similares finalidades del sindicato: el mutualismo, la colaboración para la armonía con el capital, la humanización del trabajo, el establecimiento de los principios de moral cristiana, etc. Los Principios, 13 y 14 de enero de 1944, p. 3 y 4 respectivamente.

14. Memoria, 1 de abril 1944 al 31 de marzo de 1945 del CCOC enviada a la Junta el 3 de julio de 1945, pp. 1 y 3; Actas de sesiones de la Comisión Directiva del Círculo Católico de Obreros de Córdoba, 2 de marzo de 1944, p. 385; 30 de marzo de 1944, p. 391; 13 de abril de 1944, pp. 392-393; Los Principios, 13 de enero de 1944, p. 3; Revista Eclesiástica del Arzobispado de Córdoba y Obispados sufragáneos, 1944, p. 123.

15. Memoria, 30 de junio de 1943 al 30 de junio 1944 del CCOC enviada el 22 de agosto de 1944 a la Junta de Gobierno de los Círculos, pp. 2-3; Memoria, 1 de abril 
Algunos de estos sindicatos, como los tres últimos y los metalúrgicos, seguramente fueron fundados por el Círculo para disputar espacios con otros preexistentes de tendencia izquierdista.

Las acciones de la DRSTyP en pos de la hegemonía sindical oficialista: anulación del CCOC y creación de la FOC

En abril de 1944, la derogación, de acuerdo con directivas nacionales, de la reglamentación del decreto de julio de 1943 por parte del Comisionado Federal de Córdoba abrió una etapa de mayor flexibilidad sindical.

Hacia 1944 coexistía la CGT de signo izquierdista con los sindicatos patrocinados por el CCOC favorable al gobierno militar. La primera, fruto de la reunificación en 1944 de la CGT1 y 2, estaba dirigida por el socialista Bruno Herrera (Unión Ferroviaria) y se había apartado de las acciones oficialistas de la CGT y de la Unión Ferroviaria nacional, constituyendo un foco de resistencia a la Delegación Regional de la Secretaría de Trabajo y Previsión (DRSTyP). Esta situación produjo enfrentamientos entre la central nacional y local que terminaron en julio de 1945 con la reorganización por parte del Secretariado Nacional de la CGT de la regional Córdoba, aunque este cambio no significó la destrucción del sindicalismo independiente (Di Tella, 2003: 131; Achával Becú, 2010: 233).

A mediados de 1944 llegó a Córdoba el teniente Héctor Russo, encomendado por Perón para intervenir el DPT, aduciendo incumplimiento de funciones en esta dependencia. ${ }^{16}$ Como delegado regional de la STyP, Russo tenía la misión de crear una nueva central obrera para combatir la influencia de comunistas y socialistas (Tcach, 1991: 91), aunque probablemente también para contrarrestar la participación del CCOC en un proceso de sindicalización que le resultó funcional en un primer momento pero que podía convertirse en un obstáculo para un futuro proyecto hegemónico.

Luego de la depuración del DPT de las antiguas autoridades y funcionarios vinculados al nacionalismo católico, la ahora DRSTyP evidenció mayor presencia que su antecesor mediante la declaración de las huelgas como ilegales por no actuar conforme a la ley, la mediación entre

1944 al 31 de marzo de 1945 del CCOC enviada a la Junta el 3 de julio de 1945, p. 1; La Voz del Interior, 21 de febrero de 1944, p. 7; 16 de febrero de 1944, p. 9; Los Principios, 16 de febrero de 1944, p. 5. Esta nómina prácticamente coincide con la lista de sindicatos que se reúnen en el local del Círculo e invitan al acto realizado por la visita del presidente Edelmiro Farrell a Córdoba. Los Principios, 4 de julio de 1944 , p. 1. Los obreros de la Municipalidad también fueron aconsejados por Moreno con vistas a la constitución de una entidad representativa. Los Principios, 15 de julio de 1944, p. 3.

16.La Voz del Interior, 16 de junio de 1944, p. 6; Serie Gobierno, 1944, tomo 79. 
los trabajadores y la patronal para la firma de convenios colectivos, la intervención de empresas, etc. Del mismo modo que a nivel nacional, la DRSTyP comenzó una política de atracción de trabajadores a través de la vía sindical y limitó el accionar de las asociaciones católicas en la materia. En efecto, entre septiembre y noviembre de 1944 esta dependencia emitió una resolución que según el CCOC lo afectaba en su actividad gremial. ${ }^{17} \mathrm{El}$ decreto de Asociaciones Profesionales de octubre de 1945 que establecía los sindicatos únicos por rama de industria y agrupados en una única central obrera, reafirmaba el principio de aconfesionalidad sindical de la medida de 1944, puesto que negaba la personería gremial a asociaciones constituidas sobre la base de religiones, credos, nacionalidades, razas o géneros.

Desde noviembre de 1944, los sindicatos formados al calor del Círculo progresivamente fueron abandonándolo como corolario de la medida gubernamental que impedía el accionar gremial del CCOC, por el influjo que ejercian los beneficios materiales y los reconocimientos sociales producto de la política de la STyP pero también por la postura conciliadora de Moreno, percibida como pro patronal. ${ }^{18}$

Del mismo modo que a nivel nacional, la DRSTyP se encargó de fomentar sindicatos en sectores aún no agremiados, aunque también captó aquellos recientemente creados o rediseñados por el CCOC (algunos de ellos en pugna con los de izquierda) y excepcionalmente sumó a algunos dirigentes de trayectoria. En agosto de 1945 la central oficialista Federación Obrera de Córdoba (FOC) declaraba agrupar a 10.000 obreros de los sindicatos de la Compañia de Electricidad, Transporte Automotor, Sastres y Anexos, Dulces y Anexos, Industria Cervecera, Peluqueros, Caleras y Anexos, Obreros Municipales, Mozos de Bares y Confiterias, choferes profesionales, mozos de cordel, transportes y mudanzas, encargados y porteros de departamentos, metalúrgicos de San Francisco, Oficios Varios de La Falda y de Capilla del Monte y Trabajadores Unidos de Cosquín. ${ }^{19}$ Si nos remitimos a la ciudad de Córdoba, por lo menos ocho (del transporte de pasajeros, de electricidad, sastres, confiteros, cerveceros, choferes profesionales, municipales y mudanzas) de los trece sindicatos mencionados por la FOC habian tenido vinculaciones con el Círculo. ${ }^{20}$ Esto significa que la red de sindicatos bajo la órbita del

17. "La organización y orientación de las agrupaciones sindicales. Un Memorial del Círculo Católico de Obreros" en Revista Eclesiástica del Arzobispado de Córdoba y obispados sufragáneos, 1945, pp. 58-61.

18. Testimonio del dirigente sindical de la USEOCPE Murúa en Roldán (1978: 105106 y 148).

19.La Voz del Interior, 20 de agosto de 1945, p. 13; Bauer (1999: 141).

20. Los Principios, 15 y 18 de abril de 1945, 9 y 4, respectivamente; 3 de mayo de 
CCOC fue fundamental para constituir la base de la central oficialista cordobesa, a la vez que se eliminaba a este actor como probable adversario en el ámbito gremial.

\section{La experiencia de la Federación de Sindicatos Católicos de Obreros de Mendoza y el abandono de su ideario religioso}

\section{Contexto económico-sindical de inserción de la FSCO}

Entre las actividades productivas de la provincia cuyana se destacaban el cultivo vitícola y forrajero y la minería. Hacia 1940, la población superaba poco más de 500.000 habitantes, con una quinta parte concentrada en el departamento Capital. De acuerdo con el Cuarto Censo General de la Nación (1946), de los 212.323 trabajadores remunerados mayores de 14 años, $32 \%$ estaba ocupado en la producción básica, $27 \%$ en el sector secundario y $38 \%$ en servicios. Se contabilizaron 3.601 establecimientos industriales que generaban 23.133 puestos de trabajo, 10.000 de ellos concentrados en la industria de la alimentación. ${ }^{21}$

Respecto del movimiento obrero organizado, existían sindicatos con una trayectoria reivindicativa que databa de principios del siglo XX, como los gráficos y los obreros panaderos. Otros, como los sindicatos de la Madera y de la Carne, los Toneleros y la Unión Obrera Cosmopolita, ambos de Godoy Cruz, la Unión General de Mozos de la ciudad de Mendoza, Tranviarios y Repartidores de Pan, estaban nucleados en la Federación Obrera Provincial de Mendoza (FOPM), de inclinación anarquista. ${ }^{22}$

En las décadas siguientes, la FOPM fue modificando sus inclinaciones ideológicas hacia el sindicalismo y posteriormente el socialismo y el acercamiento con los partidos políticos y entidades aliadófilos en un "frente único democrático", compuesto por los Partidos Comunista, Socialista, Socialista Obrero, Radical y movimientos de ayuda a refugiados contra el antisemitismo. Su secretario era José Cortés y la conformaban, entre otros, los sindicatos de gráficos, de la madera, de la construcción, fideeros, mozos, panaderos y cocineros, cafeteros y cockteleros. Hacia 1940, la problemática de la prescindencia politica referida al Estado

1945, p. 5 y 18 de agosto de 1945, p. 2.

21. Datos estadísticos del Instituto Técnico de Investigaciones y Orientación económica de la producción, en Guía General de Mendoza 1940, pp. 46-48 y 39; Garzón Rogé (2014: 94).

22. Los Andes, 31 de mayo de 1944, p. 5 y 11 y 18 de octubre de 1944, p. 4; Ministerio de Gobierno de la Provincia de Mendoza, Carpeta Asociaciones de obreros y empleados, 1901-1959; Garzón Rogé (2014: 95 y 97). 
provocó escisiones que derivaron en la conformación por parte de los disidentes -entre ellos Cortés- de la Central de Trabajadores Mendocinos (CTM), de preeminencia comunista. Desde junio de 1943 fue afectada por la represión, ya que sus actividades se encontraron inhabilitadas y su local clausurado. Por su parte, la FOPM fue refundada a fines de ese año bajo la dirección del gráfico Isaac Espinosa, con orientación sindicalista y una apertura al diálogo y la colaboración con las instituciones estatales laborales. ${ }^{23}$ Esta tendencia se mantendrá y consolidará durante el gobierno militar de 1943-1946.

Por último, las centrales Agrupación Gremial Argentina (AGA) y FSCO fueron herederas beneficiarias de la acción represiva sindical de la intervención federal, favorecidas con los vacios de representación dejados forzosamente por la CTM. La AGA fue la central obrera oficialista, conformada con sindicatos nuevos y en actividades laborales otrora organizadas por la CTM, como los cementistas, los metalúrgicos, los obreros de la construcción y los diversos sectores trabajadores vinculados a la vitivinicultura. Si bien reconocía como fecha de fundación el 22 de junio de $1943,{ }^{24}$ su accionar sindical recién aparece reflejado en la prensa local a principios del año siguiente. Respecto de la FSCO, fue fundada en julio de 1944 bajo la promoción de la rama adulta masculina de la AC de Mendoza (ACM), la Asociación de Hombres de la AC (AHAC), y con el asesoramiento eclesiástico del presbítero Luis Dante Piccone. La FSCO decía congregar un número importante de trabajadores concentrados en sindicatos estatales y de servicios. Nueve meses después de su conformación, en abril de 1945, modificó sus estatutos y el calificativo "Católicos" fue reemplazado por el de "Unidos".

\section{Origenes, conformación y adscripción católica de la FSCO}

En Mendoza capital, las sugerencias de la Junta de ACA acerca de la promoción sindical confesional encontraron el traductor ideal en la figura del asesor eclesiástico de la AHAC, Dante Piccone. ${ }^{25}$ En cuanto a la configuración del campo católico laico, como en el resto del país, la Acción Católica (en especial su rama masculina adulta) fue pensada como el "brazo ejecutor" de la jerarquía eclesiástica (Blanco, 2008). No obstante, la peculiaridad de la ACM fue su evidente preeminencia respecto de otras asociaciones de apostolado social, como por ejemplo el

23. Los Andes, 1 de mayo de 1939 y 1940, p. 7 y 6, respectivamente; 3 de mayo de 1940, p. 6; 1 de mayo de 1942, p.7; Garzón Rogé (2014: 95-96).

24. Los Andes, 22 de junio de 1946, p. 3

25. Cabe aclarar que en Mendoza ya existían la Federación de Maestros Católicos, la Asociación Católica de Empleadas y el Consorcio de Médicos Católicos. 
Círculo Católico de Obreros, entidad que limitaba su accionar social al mutualismo y a la publicidad en apoyo de leyes laborales. ${ }^{26}$

Por lo menos entre fines de 1943 y fines de 1944, período que abarca desde la fundación del primer sindicato de inspiración católica hasta los primeros meses de la FSCO, Piccone fue secundado en la tarea por César Soler, abogado de la curia y presidente de la ACM; el ingeniero Rodolfo Vago, director del Secretariado Económico Social de la ACM, y Oscar Roberts, de la AHAC, quienes participaron en la constitución de los primeros sindicatos católicos a través de charlas sobre temáticas sociales desde la perspectiva de la Iglesia y visitas, junto con el sacerdote y los dirigentes sindicales de las noveles agrupaciones, a los trabajadores de otras localidades para organizarlos. ${ }^{27}$ No obstante lo anterior, los dirigentes de la AHAC tuvieron una intervención muy secundaria en la conformación sindical de inspiración católica, siendo su rol identificado como de "asesoría técnica". Como veremos luego, fue Piccone el agente fundamental en la organización de los sindicatos y en el armado de lo que luego se llamó FSCO.

El primer logro de la promoción sindical confesional llegó en noviembre de 1943, con la fundación del sindicato Unión Gremial de Tranviarios, que se autodefinía como el primer sindicato católico de la provincia. ${ }^{28}$ Los estratégicos trabajadores del transporte urbano e interurbano de pasajeros siguieron siendo organizados en 1944. Así, en marzo se fundó el Sindicato de Transporte de Pasajeros y Afines, que al mes había logrado el reconocimiento de la DRSTyP. Estos tres sindicatos junto con el del Personal de la Dirección Provincial de Vialidad conformaron en julio de 1944 la FSCO. Hacia diciembre, la FSCO ya contaba con 11 sindicatos y 7.000 asociados declarados. A los cuatro mencionados se les sumaron los sindicatos del Personal del Matadero Frigorífico Mendoza; de Obreros y Empleados de la Municipalidad de la Capital; de Urbanismo y Parque; de Empleados de Salubridad de Mendoza; de Choferes Profesionales; de Obreros y Empleados de la Municipalidad de Godoy Cruz y el Sindicato Unión Gremial de Lustradores de Calzado. Posteriormente se incorporaron los repartidores de pan, los trabajadores de corralones y materiales de construcción y los

26. Círculo Católico de Obreros "Santo Domingo", Mendoza, Memoria anual. Años 1941 a 1947.

27. Boletín Oficial de la Acción Católica Argentina, septiembre-octubre de 1944, p. 134; Los Andes, 19 de noviembre de 1943, pp. 3 y 4 de marzo de 1944; Prensa Obrera, n ${ }^{\circ}$ 1 , diciembre de 1944, p. 1.

28. Los Andes, 19 de noviembre de 1943, p. 3; Guia General de Mendoza 1940, pp. 56 y 361. 
dependientes de la Compañia Electricidad de Los Andes, que pasaron a integrar a los tranviarios. ${ }^{29}$

El presidente de la FSCO era el colectivero Albino Sánchez y contaba con un asesor eclesiástico, Piccone, y un asesor letrado, el flamante abogado Jorge Lahún. Como las demás federaciones o confederaciones de iniciativa confesional mencionadas en la introducción, la FSCO evidenciaba en su denominación la adscripción católica, reforzada por la elección de su lema: "Dios - Patria - Unión". Respecto del primer término, la FSCO aclaraba que Dios era "la razón misma de existir" y que se valdría del Evangelio para pedir justicia.

Excepto los sindicatos de los tranviarios y de repartidores de pan, el resto parece tratarse de entidades nuevas que para muchos trabajadores significaron la primera aproximación a la vida sindical. En el periódico de la FSCO, Prensa Obrera, se reproducian declaraciones públicas de dirigentes que agradecian sinceramente a Piccone por su guía y enseñanzas en una actividad poco conocida para ellos. Es el caso del presidente saliente del Sindicato de Obreros del Transporte de Pasajeros y Afines, Carlos Lucero, que en ocasión de la entrega del cargo hizo una reseña de la labor cumplida y "agradeció lo mucho que el asesor eclesiástico, Rvdo. Padre Luis D. Piccone, hizo en favor del gremio, diciendo: "no omitió esfuerzos para ayudarnos a realizar una obra en la que erámos [sic] novatos. Pero secundados por hombres como él, uno tiene la facultad de sentirse veterano"". ${ }^{30}$

Es probable que en las elecciones de los futuros sindicalistas del FSCO hacia esta propuesta confesional se combinaran una genérica inclinación religiosa pero sobre todo la convocante y carismática figura de Piccone como guía en roles noveles para ellos, a semejanza del caso de los dirigentes del sindicato de Luz y Fuerza de Córdoba mencionado más arriba. Ahora bien, cabría preguntarse por la materialización de la adjetivación católica de la FSCO. En otras palabras, ¿qué injerencia concreta dispuso la Iglesia o Piccone en la cotidianidad de la Federación?, ¿qué incidencia tuvo la variable confesional en las configuraciones identitarias de sus miembros?

El sacerdote Piccone ocupaba los cargos de capellán y asesor eclesiástico de la FSCO y sus sindicatos adheridos, espacios que lo habilitaban no solo en la orientación espiritual de los asociados, sino en el acompañamiento concreto y la influencia directa en los asuntos internos de los sindicatos, al momento, por ejemplo, de brindar directivas cris-

29. Los Andes, 10 de julio de 1944, p. 9; 8 de marzo de 1944, p. 7; 29 de noviembre de 1944, p. 5; 26 de mayo de 1945, p. 5; Prensa Obrera, diciembre de 1944, pp. 1 у 3. 30. Prensa Obrera, enero de 1945, p. 4. Otro ejemplo de reconocimiento en ejemplar de marzo de 1945, p. 4. 
tianas en actos de los sindicatos, integrar comisiones de trabajadores que viajaban al interior provincial para organizar seccionales gremiales o participar de la firma de decretos sobre mejoras laborales de los sindicatos representados. ${ }^{31} \mathrm{El}$ cura explicitaba la orientación católica de la FSCO al señalar a la Iglesia como la primera que había legitimado los intereses trabajadores, para luego puntualizar que la obra de la Federación sería "esencialmente cristiana y específicamente obrera", a través de "la Verdad y la Justicia" y bajo la inspiración de la doctrina social. Asimismo, el periódico de la Federación difundía las ideas doctrinarias sobre las que se asentaba el accionar de un sindicato católico, como sinónimo de "verdadero sindicato", en contraposición a los basados en la lucha de clases. ${ }^{32}$

Por parte de los dirigentes, en Prensa Obrera aparecian algunas referencias muy generales a la religión, como el uso de los términos cristiano o católico, o la mención de la justicia social y la moral cristianas y la superación material y espiritual. ${ }^{33}$ Las alusiones a la justicia social basada en los Evangelios o la defensa de "la bandera de nuestra causa de Dios y de la Patria" del presidente Sánchez en ocasión de un almuerzo de camaradería realizado en noviembre de 1944 quizá deban entenderse en la situación que fueron pronunciadas ante la presencia de Piccone, miembros de la AHAC y autoridades de la DRSTyP invitadas. Una lectura atenta de sus palabras llama la atención acerca de que reconocía a los sindicatos de la FSCO como "específicamente cristianos" y afirmaba que eran de orden, aunque también de acción, para la defensa de derechos anteriores a la ley positiva. Por último, en una frase confusa indirectamente contemplaba la posibilidad del uso excepcional de la violencia: "Y queremos por último, que si esto [la dignidad obrera] ha de lograrse en algún caso por la violencia, Dios no lo quiera, no nos detengamos ante la violencia, porque no hay dialéctica más admisible que la dialéctica de los puños cuando se ofende a la justicia o a la Patria". ${ }^{34}$

31. Los Andes, 4 de marzo de 1944; 18 de marzo de 1944, p. 3; 3 de agosto de 1944; Prensa Obrera, $n^{\circ} 1$, diciembre de 1944 , p. 1; enero de 1945, p. 1; marzo de 1945, p. 2; Verbitsky (2007: 165). Respecto de los estatutos, se conformaban comisiones para la confección de los mismos, los que debían ser aprobados por los socios. Si bien la intervención de Piccone no aparecía mencionada, sí se destacaba que las normativas debían permitir "coordinar el plan de acción sujetándolo a principios de elevado criterio cristiano". Prensa Obrera, enero de 1945, p. 7.

32. Prensa obrera, diciembre de 1944, p. 1.

33. Prensa obrera, febrero de 1945, pp. 3 y 4. Véanse otros ejemplos de referencias al catolicismo en los números de enero de 1945, pp. 2, 4, 7 y 8; febrero de 1945, pp. 2 y 3 ; y marzo de 1945, pp. 3 y 7.

34. Prensa Obrera, diciembre de 1944, p. 1. 
Las tensiones entre lo religioso y lo sindical

Es cierto que en estos años el panorama gremial mendocino se encontraba fragmentado en diversas federaciones, pero esto no fue sinónimo necesariamente de heterogeneidad ideológica, sobre todo al pensar las relaciones con la intervención federal. Al respecto, cabe destacar que en Mendoza, a diferencia de Córdoba, el clima sindical en general y el posicionamiento político-ideológico de las centrales FSCO, FOPM y AGA eran, si no favorables, por lo menos expectantes respecto de la política laboral del gobierno. Llaman la atención los ejemplos de actos públicos y festivales organizados por estas tres agrupaciones, que cuentan como invitados especiales a los funcionarios de la DRSTyP, o la presencia de referentes gremiales en los banquetes oficiales y en actos de adhesión al gobierno nacional. ${ }^{35}$ Asimismo, las modalidades de expresión y reclamo sindicales se hallaban reducidas a petitorios o pedidos de conciliación, mientras que las acciones como el trabajo a reglamento, el boicot o las huelgas parecían impensables en esas condiciones. Considero que para el logro de este ambiente de negociación y de mesura gremial generalizada fueron fundamentales dos factores: la exitosa anulación comunista vía represión, que eliminó una corriente de potencial oposición sindical, y la flexibilidad ideológica de las dirigencias sindicalistas de la FOPM que desde antes del golpe ya habian mostrado acercamientos con las autoridades estatales del DPT, quienes continuaron en su cargo luego de junio de 1943. Este contexto calmo nos explica también la urgencia relativa por parte de la intervención federal de contar con apoyo sindical propio, a través de una central oficialista como fue la AGA. No obstante, este estado de situación fue efimero; hacia principios de 1945 adquirió nueva fisonomía a partir de la liberación de los detenidos políticos, la conformación de un frente político partidario y sindical opositor y las implicancias de la conversión de la FSCO en Federación de Sindicatos Unidos Obreros (FSUO).

Como veremos a continuación, las mejoras obreras conseguidas por la FSCO sobre la base del diálogo y la negociación en las oficinas de la DRSTyP y en Buenos Aires con Perón eran limitadas, con convenios constantemente incumplidos por los empleadores. En este contexto, la mención de las palabras acción y violencia podrian leerse como claves de lo que la dirigencia de la FSCO estaba pensando y como anticipatorias de un quehacer sindical liberado de influencias doctrinarias religiosas.

En efecto, si repasamos el accionar sindical de la FSCO en sus meses de existencia, la impresión que dejan las declaraciones sobre los logros

35. Algunos ejemplos en Los Andes, 30 de julio de 1944, p. 4; 31 de agosto de 1944, p. 3; 4 y 27 de noviembre de 1944, p. 3 y 6, respectivamente y 22 de abril de 1945, p. 7. 
alcanzados como resultado de una política conciliadora es de un disimulado inconformismo. Algunas de los modestos avances conseguidos que mencionaban los sindicatos de tranviarios o de los trabajadores del matadero eran promover una política de entendimiento con la patronal, ser más respetados y tener derecho a réplica, aunque se reconocía que los aumentos salariales apenas los "saca[ban] momentáneamente de la total indigencia". La falta de contundencia en las mejoras era justificada porque "la lucha es cruenta y factores adversos retardan la justicia social". ${ }^{36}$

En el caso de la acción sindical de la FSCO, las directrices fundadas en la armonía social y seguramente los controles eclesiásticos para circunscribir las acciones sindicales al diálogo, combinados con la actitud de una intervención federal que se valía de la generalizada anuencia gremial a sus políticas para ralentizar cambios de base, hicieron que la mesura y la espera inercial aconsejada tanto por la Iglesia como por la DRSTyP, se contrapusieran a los intereses de los trabajadores. Estas limitaciones, sumadas a las exigencias de las autoridades de Trabajo de adecuar los estatutos en clave laica, se resolvieron mediante la ruptura de la Federación con la Iglesia (Blanco, 2016).

Cuando "Unidos" reemplazó a "Católicos". Rupturas y mayor libertad de acción

Algunos sindicatos de la FSCO como el de Transporte y Afines y el de Vialidad Provincial habían sido reconocidos por la DRSTyP en carácter de entidades obreras, de acuerdo a la ley provincial 1376, sancionada en $1939 .{ }^{37}$ Sin embargo, lo anterior no era sinónimo de personería gremial, la cual era denegada por la Delegación debido a la confesionalidad contenida en sus reglamentaciones.

Esta problemática estaba instalada en la FSCO desde noviembre de 1944 , cuando varios de sus sindicatos entrevistaron al interventor federal Aristóbulo Vargas Belmonte por el tema y se plantearon la necesidad de modificar parcialmente los estatutos. ${ }^{38}$ Un actor externo a la Federación pero parte interesada del mundo sindical, la FOPM, manifestaba su apoyo a la DRSTyP en su negativa a otorgarles la personeria gremial, dada la "anormalidad estatutaria de los solicitantes, por cuanto no se ajusta a la prescindencia confesional del movimiento obrero y a la ingerencia

36. Prensa Obrera, diciembre de 1944, pp. 2, 4, 5 y 7.

37. Los Andes, 7 y 16 de abril de 1944, p. 4 y 7, respectivamente; Prensa Obrera, diciembre de 1944 , p. 7 .

38. Los Andes, 8 y 20 de noviembre de 1944, p. 5 y 4 respectivamente; 7 de diciembre de 1944 , p. 3. 
[sic] en la dirección de las aludidas entidades, de personas ajenas a la práctica efectiva de tareas propias de los obreros". ${ }^{39}$

En marzo de 1945 la FSCO realizó una reunión para tratar el tema de cambios en los estatutos. En ese acto, y según el testimonio del asesor letrado Lahún, fue rechazado el anteproyecto de estatutos preparado para sindicatos católicos presentado por él, con "la oposición sistemática que se hacía a los principios específicamente cristianos que se hacian en el texto, y que son inspirados en la más pura doctrina social cristiana contenida en las Encíclicas papales". En la asamblea del 6 de abril avanzaron aún más en la desaparición de cualquier vestigio de confesionalidad y modificaron el nombre de la entidad "Federación de Sindicatos Católicos Obreros" por "Federación de Sindicatos Unidos Obreros". Finalmente, en mayo en una asamblea general extraordinaria se aprobaron las enmiendas a algunos artículos de los estatutos para adaptarlos a las exigencias de la DRSTyP. ${ }^{40}$

Lo anterior provocó conflictos con algunos sindicatos que se escindieron, como el de municipales de Godoy Cruz, con el asesor letrado Lahún, que renunció a su cargo, y con la Iglesia, que retiró su apoyo a Prensa Obrera. ${ }^{41}$

De todas maneras, el cambio de denominación no fue meramente cosmético ni estratégico en pos de la obtención de la personería gremial, sino que significó un giro radical en las modalidades de acción sindical que venía desplegando la Federación y una adaptación a sus necesidades en la defensa más efectiva de los intereses de los trabajadores. ${ }^{42}$ En efecto, la ruptura con los inicios confesionales coincide con la emergencia de conflictos latentes entre algunos sindicatos pertenecientes a la FSUO y la patronal y el Estado, que protagonizaron los obreros públicos y del transporte entre abril y mayo de 1945. Esta nueva etapa de mayor firmeza e intransigencia sindical tuvo resultados positivos: la exigencia del sindicato de Transporte acerca de las inmediatas reincorporaciones fue cumplida a los pocos días, al tiempo que las remuneraciones de los obreros de la Municipalidad fueron mejoradas. ${ }^{43}$ Asimismo, la cordialidad con la DRSTyP, que era recalcada tanto por Prensa Obrera como por los comunicados de la Federación en la prensa local, dio lugar a

39. Los Andes, 23 de abril de 1945, p. 7.

40. Prensa Obrera, mayo de 1945, p. 1; Los Andes, 13 y 17 de abril de 1945, p. 7 y 4 respectivamente; 23 de mayo de 1945, p. 5.

41. Los Andes, 23, 11 y 14 de abril de 1945, pp. 5, 5 y 4, respectivamente.

42. Al respecto, traigo a colación el caso ya presentado del sindicato de Luz y Fuerza de Córdoba, trabajado en Blanco (2010: 151-152).

43. Los Andes, 17 de abril de 1945, p. 3 y 19 de abril de 1945, p. 5; Prensa Obrera, mayo de 1945, p. 1. 
virulentas críticas por la inocuidad del organismo de Trabajo, evidenciada en los numerosos convenios, resoluciones y decretos incumplidos por los empleadores, lo cual afectaba a los asalariados en cuanto a suspensiones injustificadas, falta de uniformes, desconocimiento de la antigüedad, retención indebida de sueldos, etc. El reemplazo del titular de la Delegación fue bienvenido por la FSUO, ${ }^{44}$ aunque este recambio no fue óbice para que la espiral conflictiva continuara con la huelga del sindicato de Vialidad, que posteriormente se convirtió en general con el apoyo solidario del resto de los gremios de la FSUO. ${ }^{45}$

Estas acciones reivindicativas deben entenderse en un contexto de mayor efervescencia política, con presos políticos ya liberados y con la organización y expresión pública de un frente opositor autodenominado progresista (Garzón Rogé, 2014). De todas maneras y por todo lo expuesto, considero que no hay que minimizar el quiebre que la ruptura con la Iglesia, de posición contraria a las huelgas, ${ }^{46}$ produjo en las prácticas sindicales de la ahora FSUO.

\section{Consideraciones finales}

Las iniciativas sindicales confesionales que desde 1943 emprendieron el CCOC y la ACM, significaron una mayor presencia pública de la Iglesia en el movimiento obrero organizado y coincidieron con una de las etapas de mayor represión sindical y política de la historia del país y con el proceso formativo del peronismo. No obstante, este contexto político favorable fue condición necesaria pero no suficiente para la emergencia de los proyectos sindicalizadores de inspiración católica. En otras palabras, la represión sindical gubernamental dejó vacíos de representación que pudieron ser aprovechados por los agentes católicos solo en algunas diócesis. Así, los campos católicos de Córdoba y Mendoza presentan similitudes en el grado de desarrollo y maduración del asociacionismo social, con laicos motivados en su interés por los sectores trabajadores por curas y asesores eclesiásticos carismáticos,

44. Los Andes, 6 y 16 de mayo de 1945, p. 9 y 8, respectivamente; 28 de mayo de 1945, pp. 4 y 5; Prensa Obrera, mayo de 1945, p. 1.

45. Los Andes, 28 de junio de 1945; 30 de junio de 1945, pp. 5 y 6; 1 y 2 de julio de 1945, pp. 7 y 11 , respectivamente.

46. En agosto de 1945, unos meses después del conflicto huelguístico de vialidad apoyado por la FSUO, el obispo Alfonso María Buteler reiteró a los miembros de la $\mathrm{ACM}$ que "Las huelgas y manifestaciones tumultuosas no son el medio normal ni el más apto para conducirnos al discernimiento de lo que es justo y conforme a verdad. Por tal motivo es prudente una actitud de reserva cuando se advierte preferencia y repetición en el empleo de tales medios", Boletin Oficial del Arzobispado de San Juan de Cuyo y Obispados sufragáneos de Mendoza y San Luis, 1945, p. 288. 
como Moreno y Piccone. Empero, cable aclarar que más allá de que las agendas de acción social de la ACA y de los CCO hicieron inteligibles estas iniciativas, las mismas se presentaron atomizadas y sin mucha vinculación con proyectos similares llevados a cabo a nivel nacional o en otras diócesis. Tal vez esto pueda explicarse por dos razones: primero porque fueron experiencias temporalmente muy cortas que, por prohibición gubernamental en el caso de Córdoba y por disidencia gremial en Mendoza, no llegaron a consolidarse. Segundo, porque parecieron ser la materialización de cruzadas de entusiastas eclesiásticos aislados secundados por un grupo de laicos, y no a la inversa.

Los pasos iniciales del gremialismo católico fueron dados en un contexto político favorable para la parcialidad católica, con intervenciones federales que en su primera etapa y en línea con el gobierno nacional, habian prohibido toda actividad política, clausurado entidades de carácter comunista y perseguido y encarcelado a personas sospechadas de actividades izquierdistas.

De todas maneras, cabe reconocer que los diferentes mapas sindicales vernáculos preexistentes condicionaron la actuación de las intervenciones federales, las características de inserción de las iniciativas gremiales confesionales y el lugar de las mismas en la estrategia sindical hegemónica del gobierno militar. En este punto es donde podemos marcar las mayores diferencias.

En Córdoba, el golpe de Estado irrumpió en un sindicalismo fragmentado ideológicamente al que no pudo disuadir fácilmente, con organizaciones gremiales bajo dirección socialista y comunista, como los gráficos, mozos, panaderos y obreros de la construcción, que mantuvieron distancia del gobierno militar y luego se posicionaron opositores al naciente peronismo. El CCOC aprovechó vacíos de representación forzados y brindó servicios mutuales y de asesoramiento gremial que atrajeron a dirigentes de reestructurados y nuevos sindicatos, con la venia de las autoridades del DPT, de orientación nacionalista católica. Junio de 1944 marca un quiebre en este sentido, con la nueva orientación que asume la ahora DRSTyP dirigida por Russo en pos de la hegemonía oficialista en el ámbito sindical. Entre las estrategias adoptadas pueden mencionarse la creación de gremios paralelos y la fundación de nuevos sindicatos en áreas todavía no agremiadas, como ocurrió en otros puntos del país. Sin embargo, en Córdoba el frente sindical oficialista contó con la particularidad de conformarse también a través de la atracción de sindicatos preexistentes que se encontraban bajo la promoción del CCOC, desplazado legalmente de la agremiación. Así, estos sindicatos sirvieron de base para la conformación de la central oficialista FOC, a la vez que se eliminó una potencial fuente de competencia representada en el Círculo. 
En Mendoza la interrupción institucional no fue tan disruptiva como en Córdoba, primero por la continuidad que existió entre los funcionarios del DPT del gobierno demócrata y el militar, y segundo por la actitud colaboracionista y negociadora de las dirigencias sindicales de la FOPM para con las autoridades laborales. La similitud con Córdoba solo aparece en los vacíos de representación forzados, que fueron ocupados por la AGA y la FSCO, a través de la fundación de sindicatos paralelos y la agremiación de sectores laborales todavía no organizados, respectivamente. A diferencia de Córdoba, estas tres centrales se mantuvieron alineadas con la intervención federal y atentas a la concreción de sus postulados sociales, situación que le brindó al gobierno por un lado una base sindical de apoyo y por otro un margen de maniobra para dilatar las mejoras prometidas por el Estado o la patronal como empleadores. Esta situación comenzó a complejizarse desde 1945, debido a una mayor efervescencia política resultado de la liberación de presos políticos, efervescencia que la FSUO, ya independizada de la adscripción católica, alimentó con sus acciones reivindicativas.

\section{Bibliografía}

Achával Becú, Inés (2010), Las culturas politicas y el origen del peronismo en Córdoba (1943-1947), Córdoba: inédito.

Bauer, Francisco (1999), Los trabajadores del transporte urbano de pasajeros en Córdoba, Córdoba: Talleres gráficos de Q\&Q Gráfica.

Blanco, Jessica (2008), Modernidad conservadora, y cultura política: Acción Católica de Córdoba (1931-1941), Córdoba: Facultad de Filosofia y Humanidades.

- (2010), "Religión, sindicalismo y política en los años 40: una revisión sobre la participación católica en los sindicatos durante los años formativos del peronismo" en Gardenia Vidal y Jessica Blanco (comps.), Catolicismo y política en Córdoba, siglos XIX y XX, Córdoba: Ferreyra, pp. 133-163.

- (2016), "De "Católicos" a "Unidos". Las tensiones entre adscripción religiosa y acción sindical en la Federación de Sindicatos Católicos de Obreros de Mendoza (1944-1945)", en Gardenia Vidal y Jessica Blanco (eds.), Espacio público en Argentina, fines s. XIX-primera mitad s. XX. Partidos, catolicismo, sociabilidad..., Córdoba: Brujas, pp. 189-211.

Di Tella, Torcuato (2003), Perón y los sindicatos. El inicio de una relación conflictiva, Buenos Aires: Ariel.

Ferrero, Roberto (2009), Del mutualismo al Cordobazo. Breve historia del movimiento obrero en Córdoba, Córdoba: Cepen.

Garzón Rogé, Mariana (2014), El peronismo en la primera hora. Mendoza, 1943-1946, Mendoza: EDIUNC.

Roldán, Martha (1978), Sindicatos y protesta social en la Argentina. Un 
estudio de caso: el Sindicato de Luz y Fuerza de Córdoba (1969-1974), Ámsterdam: CEDLA.

Tcach, César (1991), Sabattinismo y peronismo, Buenos Aires: Sudamericana.

Verbitsky, Horacio (2007), Cristo vence: la Iglesia en la Argentina. Un siglo de historia politica (1884-1983), tomo I, Buenos Aires: Sudamericana. 